\title{
Produção de polvilho a partir do amido de mandioca: busca de alternativas para otimização do processo de produção em indústrias polvilheiras do município de Conceição dos Ouros, Minas Gerais, Brasil
}

\author{
Rafael Machado Felix de LIMA ${ }^{1}$ \\ Eduardo Inácio da SILVA \\ Maria Angélica CRIVELARO ${ }^{3}$ \\ Sandra Aparecida de ALMEIDA ${ }^{4}$ \\ Valdomiro Vagner de SOUZA 5
}

(1) Licenciado em Química, Faculdades Integradas ASMEC / UNISEPE, rafaelmachadolima@hotmail.com

(2) Licenciado em Química, Faculdades Integradas ASMEC / UNISEPE, eduardoinaciodasilvainacio@yahoo.com.br

(3) Licenciado em Química, Faculdades Integradas ASMEC / UNISEPE, angelica_crivelaro@hotmail.com

(4) Licenciado em Química, Faculdades Integradas ASMEC / UNISEPE, sandrinha_costas@ hotmail.com

(5) Professor Assistente Mestre, Departamento de Ciências Biológicas - Centro Universitário de Itajubá (FEPI); Professor colaborador, Faculdade de Ciências Médicas "Dr. Antônio Garcia Coutinho", Universidade do Vale do Sapucaí (UNIVAS), valdomirovagner@gmail.com

Recebido em: 22/08/2012 - Aprovado em: 15/12/2012 - Disponibilizado em: 30/12/2012

\section{RESUMO:}

A mandioca (Manihot esculenta crants) é uma planta de origem brasileira, da qual se obtém o polvilho. O polvilho azedo e fermentado, além de apresentar sabor e odor característico, pode sofrer alterações em suas propriedades físicoquímicas. Diante disso, o processo de produção deve ser cuidadosamente planejado. O presente trabalho objetivou a otimização do processo de produção do polvilho, buscando melhorias e tornando-o mais competitivo no mercado. $\mathrm{O}$ experimento foi conduzido em três indústrias polvilheiras, localizadas na cidade de Conceição dos Ouros, sul de Minas Gerais. Foram observadas todas as etapas do processo de produção, desde a chegada da mandioca na fábrica até o estágio final. A partir dessas observações fez-se uma análise sistemática, destacando pontos importantes a serem otimizados. Observou-se que as indústrias avaliadas necessitam de modificações urgentes em seu processo de produção, para que se consiga maior qualidade de seu produto.

Palavras-chave: amidos e féculas. Fermentação. mandioca

\begin{abstract}
:
Cassava (Manihot esculenta crants) is a plant from Brazil, from which we get the sprinkles. The sour and fermented, besides having a characteristic odor and flavor, can undergo changes in their physicochemical properties. Thus, the production process must be carefully planned. This work aimed at optimizing the production process the flour, seeking improvements and making it more competitive. The experiment was conducted in three industries polvilheiras, located in the city of Conception of Diamonds, south of Minas Gerais. We observed all stages of production, since the arrival of the cassava plant to the final stage. From these observations we did a systematic analysis, highlighting important points to be optimized. It was observed that the measured industries require urgent changes in their production process, so as to achieve higher quality of the product.
\end{abstract}

Keywords: starch and fecula. fermentation. cassava.

\section{INTRODUÇÃO}

A mandioca, Manihot esculenta

Crants é uma planta de origem brasileira, que começou a ser cultivada pelos índios, existindo aproximadamente 98 espécies conhecidas no gênero Manihot (euphorbiaceae), sendo a mesma utilizada como alimento desde as civilizações précolombianas. É uma planta de terreno aberto, quente e seco, que cresce com vigor, sem se 
ramificar, possuindo período de safra de janeiro a julho (CONCEIÇÃO, 1981).

A mandioca, além de estar presente diretamente na cozinha brasileira, ela também se apresenta indiretamente através de seus subprodutos, tais como: biscoitos, sequilhos, pão de queijo, etc. Estes têm como principal ingrediente o polvilho, que é obtido através do amido da mandioca (PÃO DE QUEIJO, 2001).

Para tanto, sabe-se que existem duas variedades de polvilho conhecidas: (i) a fécula, também chamada de polvilho doce e; (ii) o polvilho azedo, que é obtido a partir da fermentação deste primeiro (CÁRDENAS \& BUCKLE, 1980).

A classificação do polvilho, pela legislação brasileira, se dá por normas técnicas para alimentos e bebidas. Essa classificação é baseada no teor de acidez que, para o produto fermentado, deve ser no máximo de $5 \mathrm{~mL}$ de $\mathrm{NAOH} / 100 \mathrm{~g}$ (Lorenzi et al., 1993). No entanto, é importante salientar que cerca de $60 \%$ da acidez total é devido ao ácido lático, o que confirma a participação da bactéria ácido-lática no processo. Outros $40 \%$ são ácido acético e uma mistura do mesmo com o ácido butírico (REGINATO et al., 2009).

Considerando essa classificação, considera-se que a fermentação da fécula pode fazer com que o amido aumente seu valor nutritivo. Isso ocorre por um aumento na porcentagem de proteínas, (já que a mandioca é deficiente em proteínas) (CEREDA \& CATÂNEO, 1986).

\section{Segundo CEREDA (1987), a}

fermentação natural do polvilho envolve considerável variedade de microorganismos, que produzem um aumento na acidez titulável do produto.

Na fabricação do polvilho ocorre uma série de processos distintos. A mandioca é comprada de produtores rurais e transportada para as indústrias, chegando ainda fresca na fábrica e pronta para se começar a produção.

O processo de fermentação é realizado através de tanques, cobrindo-se o polvilho com uma camada de água de aproximadamente $15 \mathrm{~cm}$, permanecendo no prazo mínimo de trinta dias.

Posteriormente, o polvilho é retirado do tanque de fermentação em forma de pedras que são jogadas em um triturador, que as quebram em partes menores, facilitando assim o manuseio do mesmo para o local de secagem em grades de tela e bambu. (REGINATO, 1997)

Neste local, o polvilho passa por uma peneira, cuja função é retirar toda sujeira possível. Em seguida, o polvilho cai dentro de um misturador, quem tem dupla função: refinar e misturar.

Posteriormente, ao sair deste misturador, o polvilho passa por outra peneira de tela mais fina, a fim de retirar impurezas de proporções menores. Realizado este 
processo de refinagem, o polvilho vai para o embale. (Figura 1).

Figura 1 - Fluxograma do processo geral da produção de polvilho.

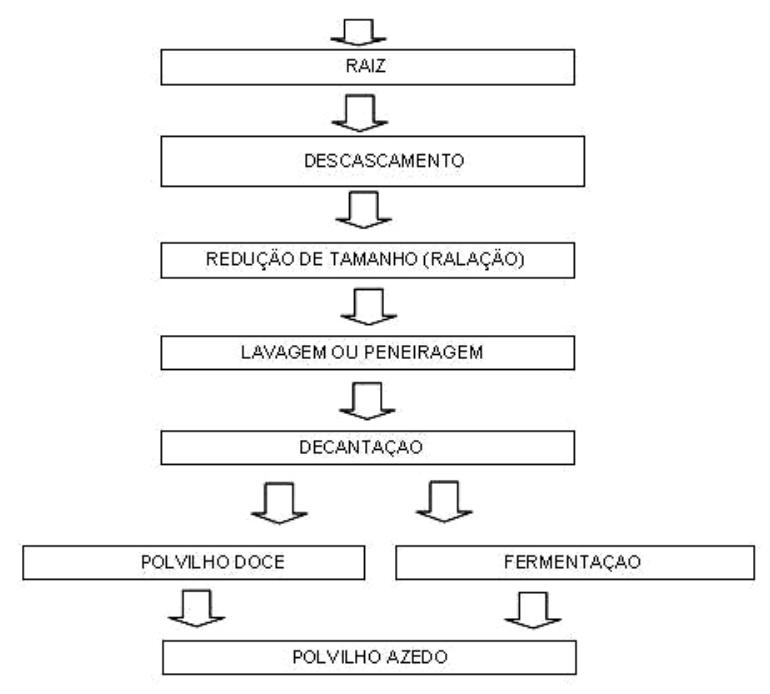

Fonte - Dos próprios autores.

É importante salientar que o polvilho azedo depois de fermentado, além de apresentar sabor e odor característico, sofre ainda, alterações em suas propriedades físicoquímicas, apresentando maior absorção de água e menos viscosidade em comparação com o polvilho doce (ASCHERI \& VILELA, 1995).

Segundo dados técnicos obtidos com a EMATER de Conceição dos Ouros, a cidade é responsável pela maior parte da produção de polvilho azedo do estado.

No município existem 150 produtores de pequeno, médio e grande porte, cultivando uma área de 350 metros de mandioca.
As 20 fábricas de polvilho no município, em conjunto, no ano de 2008, processaram 52.000 toneladas de raízes de mandioca para a produção de polvilho, sendo 10.400 toneladas colhidas no município de Conceição dos Ouros e 41600 toneladas vindas de municípios vizinhos.

No ano de 2009 foram processadas 35.970 toneladas de raízes de mandioca, sendo 7.154 toneladas produzidas no município e 28.816 toneladas vindas de municípios vizinhos. No ano de 2008 a cidade produziu 13.000 toneladas de polvilho, havendo uma queda, em 2008, de 30\% da produção, tendo produzido 8.942,5 toneladas de polvilho (CARVALHO et al., 1996).

Como o município se destaca pelo grande número de indústrias de polvilho e alto volume de produção, faz-se necessário à busca de alternativas viáveis de melhoria no processo de produção e otimização.

Contudo, salve melhor juízo, não existe na literatura trabalhos publicados tratando do desenvolvimento de metodologias e/ou otimização desse sistema de produção. A realização de mais pesquisas nesta área seria útil, pois possibilitaria a pequenos produtores a obtenção de informações acessíveis sobre como obter melhorias no sistema de produção de suas indústrias.

Desta forma, os objetivos principais do presente artigo foram estudar toda a metodologia do processo de produção de polvilho, destacando os pontos falhos e 
sugerindo melhorias no processo de produção e ainda, destacar o polvilho como produto amiláceo tornando-o mais competitivo no mercado de amidos modificados.

\section{MATERIAIS E MÉTODOS}

Trata-se de uma pesquisa explicativa experimental, que foi conduzida em três indústrias polvilheiras, localizadas na cidade de Conceição dos Ouros, sul de Minas Gerais, durante o período da entressafra da região (junho a novembro de 2010). Foram observadas todas as etapas do processo de produção, desde a chegada da mandioca na fábrica até o estágio final, quando o produto está pronto para consumo. A partir dessas observações fez-se uma análise prévia, destacando os pontos mais importantes e que, portanto, necessitam ser otimizados.

\section{RESULTADOS E DISCUSSÃO}

Mediante análise dos resultados, observou-se a presença de contaminantes no produto final, quando se obtêm o polvilho doce e/ou polvilho azedo, tais como materiais de origem mineral. Acredita-se que isso ocorreu devido a sua exposição e secagem ao sol. Como não existe pavimentação nos locais de secagem, conforme Figura 2, e o fato de muitas fábricas se localizarem próximas de estradas, a ação do vento pode ser a maior contribuição para essa contaminação.
Figura 2. Jiraus de secagem do polvilho.

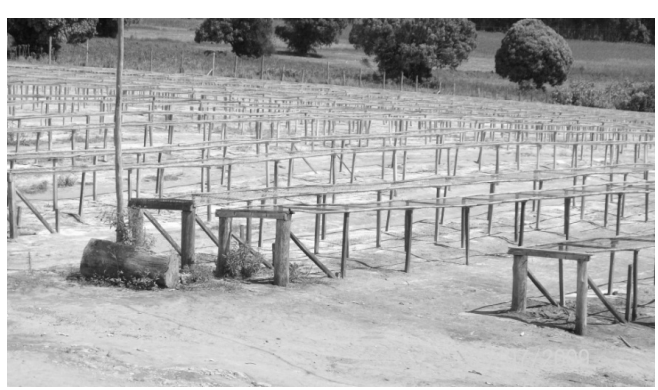

Fonte - Dos próprios autores.

Para evitar este fator, sugere-se o plantio de árvores ao redor, com a intenção de amenizar a ação dos ventos, ressaltando que é indispensável à manutenção da grama ou a pavimentação em baixo dos jiraus de secagem.

Em relação ao processo de fermentação (Figura 3), observou-se que o mesmo ocorre em tanques de alvenaria revestidos com cerâmica, existindo, portanto, uma grande produção de ácidos orgânicos, o que acaba atraindo vários tipos de insetos e conseqüentemente, comprometendo o produto. Para se evitar essa contaminação, sugere-se a instalação de cobertura nos tanques com telas finas ou tecidos, de modo a impedir a entrada dos insetos. 
Figura 3. Polvilho no tanque de fermentação.

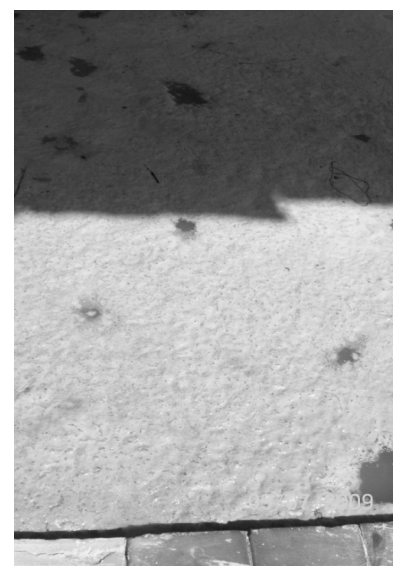

Fonte - Dos próprios autores.

Em relação ao descarte da água da mandioca, observou-se que a mesma é eliminada num barreiro a céu aberto, e em considerável quantidade e concentração. Devido à elevada carga de matéria orgânica e ácido cianídrico ( $\mathrm{HCN})$, isso contribui para o surgimento de sérios problemas ao meio ambiente.

Para a resolução e/ou minimização desse problema, sugere-se a realização de prétratamento desse resíduo antes de descartá. Para uma boa estrutura de aproveitamento é interessante a construção de tanques de armazenagem, preferencialmente azulejados, de modo que o líquido fique em repouso. Após, uma parte de sua composição se decantará na forma de um lodo sólido, sendo posteriormente, o sobrenadante deslocado para outro tanque com um filtro de areia e brita. Após, o mesmo poderá ser descartado, apresentando-se em menor concentração e com menor carga de matéria orgânica.

Outra sugestão envolveria o aproveitamento do lodo sólido, que quando seco, apresenta a possibilidade de ser reutilizado como adubo orgânico.

Também pode-se perceber que a manipueira, altamente poluente, é descartada das industrias a céu aberto. A mesma poderia, ao invés disso, ser aproveitada como fertilizante, visto que é rica em nitrogênio $(\mathrm{N})$, fósforo $(\mathrm{P})$, potássio $(\mathrm{K})$ e magnésio $(\mathrm{Mg})$. Recomenda-se também, a mistura de 1/1 L de água e manipueira, sendo a aplicação dessa mistura de dois a quatro litros por metro de sulco de cultivo, deixando o solo descansar por oito ou mais dias após a aplicação (CEREDA, 1983).

Outra sugestão seria o aproveitamento da manipueira para a produção de biogás, importante fonte de energia renovável.

Também observou-se que, em nenhuma das etapas do processo de produção, houve a realização de algum tipo de controle microbiológico, não havendo inclusive, a realização de análise do produto acabado. Essas análises são essenciais e deveriam, portanto, ser realizadas por profissionais qualificados, em distintos momentos da produção,

Outro fato observado é a ausência de higienização nos maquinários utilizados, (Figura 4). Salienta-se a necessidade da completa higienização de todos os 
equipamentos utilizados, inclusive os maquinários através do uso de detergentes e produtos antimicrobianos específicos.

Figura 4. Processo de lavagem e descascamento da mandioca.

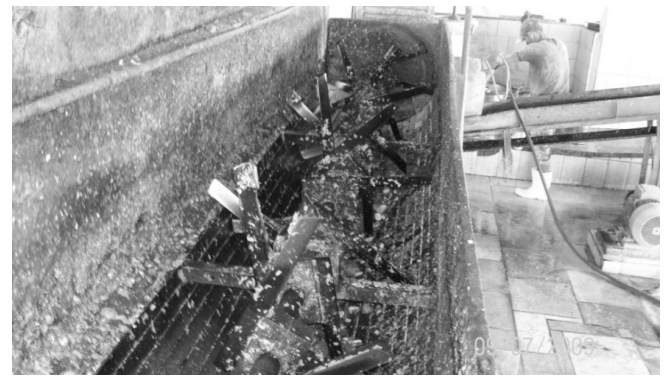

Fonte - Dos próprios autores.

No local onde se encontra os tanques de fermentação e a decantação, conforme a Figura 5, a higienização também é falha, o que provoca grande contaminação por sujeiras. A cobertura que protege os tanques de fermentação são rústicas e não apresentam nenhuma proteção no teto e isso acaba por contribuir com o aumento da contaminação, pois encontra-se presos a esses telhados ninhos de pássaros e teias de aranha. Sugerese forragem dos telhados com PVC ou gesso ou ainda a substituição do mesmo por coberturas metálicas com folhas de zinco, o que além de melhorar a higienização contribuirá para aceleração no processo de fermentação devido a uma maior absorção de calor.
Figura 5. Tanques de fermentação expostos a contaminantes.

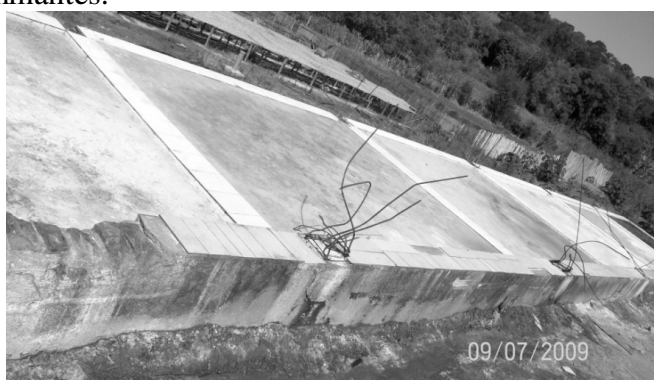

Fonte - Dos próprios autores.

Também notou-se que os trabalhadores não utilizam nenhum tipo de equipamento de proteção individual. No processo de transferência do polvilho doce (Figura 6), que se encontra na decantação, para os tanques de fermentação, os empregados trabalham muitas vezes sem camisa, descalços, pisando sobre o alimento, e inevitavelmente, suor e pelos corporais contaminam o produto.

Uma alternativa seria a utilização de equipamentos de proteção individual pelos colaboradores, que além de proteger os mesmos de acidentes laboriais, ainda evitaria a contaminação do produto.

Figura 6. Transferência do polvilho doce da decantação para os tanques de fermentação.

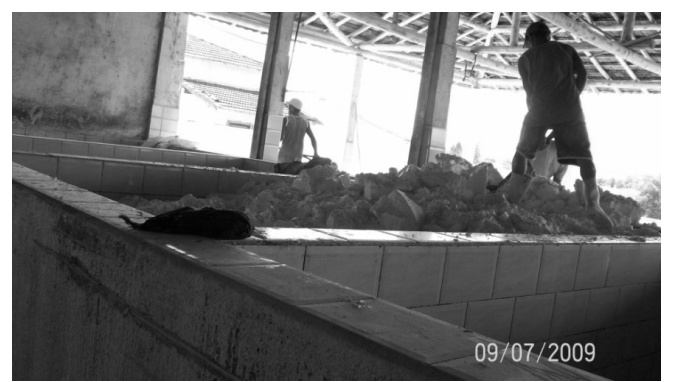

Fonte - Dos próprios autores. 
Considerando os dejetos orgânicos produzidos, (Figura 7), há também a necessidade imediata da dedetização em toda a fábrica, evitando a presença de roedores e outros animais.

Figura 7. Resíduos da produção de polvilho.

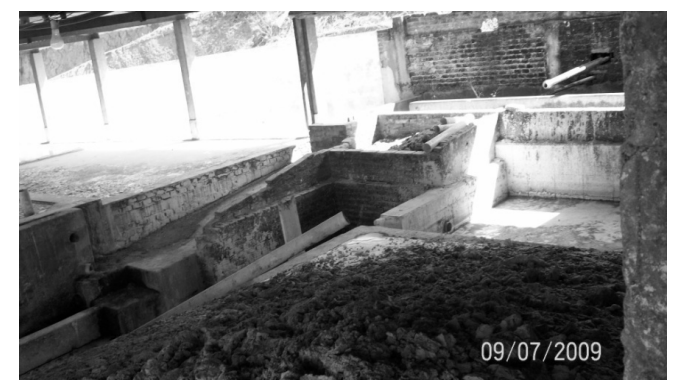

Fonte - Dos próprios autores.

No depósito de armazenamento do polvilho seco nota-se que o mesmo é colocado em sacos de $50 \mathrm{Kg}$, muitas vezes encostados nas paredes, o que compromete a conservação do alimento principalmente em períodos chuvosos onde o mesmo pode se umedecer. Sugere-se a utilização de estrado

\section{REFERÊNCIAS}

ARALDI, R.; FREITAS L. S. P.; NETO C. S. V.; MUNIZ S. C. A.; REZENDE, R.; GONÇALVES A. C. A. Aplicação de água residuária de fecularia de mandioca na cultura da aveia. In: Anais da $58^{\circ}$ reunião anual da SBPC. Florianópolis, 2006.

ASCHERI, D.P.R.; VILELA, E. R. Alterações do polvilho da mandioca pela fermentação,no fabrico de biscoitos. Pesquisa sobre o chão para que o produto não tenha contato com a parede.

Todavia, considerando que muitas das ferramentas utilizadas nas indústrias polvilheiras são de ferro e, sabendo-se que o contato com o polvilho úmido na presença do oxigênio do ar se oxidam e acabam por sofrer corrosão com o tempo, salienta-se a necessidade da substituição por ferramentas de aço inoxidável.

\section{CONCLUSÕES}

Mediante análise dos resultados, pode se concluir que as indústrias polvilheiras analisadas precisam buscar medidas imediatas para a otimização do processo de produção. O seguimento das recomendações de otimização descritas nesse trabalho certamente irá, não somente garantir um produto de melhor qualidade, como também fornecer subsídios para que o produto se torne mais competitivo no mercado nacional.

Agropecuária Brasileira, Brasília, vol.30 n.2, p. 269-279. Fev. 1995.

BRANDÂO, V. Fécula de mandioca: Alimentos farináceos. Cultura gastronômica, glossário de alimentos, fev.2005. Disponível em: < http://correiogourmand.com.br > .Acesso em 09 de set de 2009.

CÁRDENAS, O.S.; BUCKLE, T.S. Sour cassava starch production: A preliminary study. Journal of Food Science, Bogotá, vol. 45, 1980, p.1509-1512. 
CARVALHO, E. P; CANHOS, V. P; RIBEIRO, V. E. Polvilho azedo: aspectos físicos, químicos e microbiológicos. Pesquisa Agropecuária Brasileira, Brasília, v.31, n.2, 1996, p.129-137.

CEREDA, M.P. Tecnologia e qualidade do polvilho azedo. Informe Agropecuário. Belo Horizonte, v.13, n.145, 1987, p.63-68.

CEREDA, M.P.; CATÂNEO, A. Avaliação de parâmetros de qualidade da fécula fermentada de mandioca. Revista Brasileira de Mandioca, Cruz das Almas, v.5, n.2, 1986, p.55-62.

CEREDA, M.P. Propriedades gerais do amido. FUNDAÇÃO CARGILL, Culturas de tuberosas latino americanas, mar. 2002b. Disponível em: http://www.raizes-ong.org.br. Acessado em 12 de Nov de 2009.

CEREDA, M.P. Tecnologia e qualidade do polvilho azedo. Informe Agropecuário, Belo Horizonte, v.13, n.3, 1983, p.297-304.

CONCEIÇÃO, A.J. A mandioca. São Paulo: Nobel. 1981

CREPALDI C, I. Origem, evolução e geografia da mandioca: uma revisão.

Sitientibus, Feira de Santana, n.10, 1992, p.89-94.

EMPRESA BRASILEIRA DE PESQUISA AGROPECUÁRIA - Embrapa. Cultura da mandioca. Centro Nacional de Pesquisa de Mandioca e Fruticultura, fev.1997. Disponível em: < http://www.cnpmf.embrapa.br/mandioca.htm \#topo > acessado em 10 de jan. 2010

LORENZI, J.O; RAMOS, M. T. B.; MONTEIRO, D. A.; VALLE, T. L.; JÚNIOR, G. G. Teor de ácido cianídrico em variedades de mandioca cultivadas em quintais do estado de São Paulo. Bragantia, Campinas, v.52, n. 1, 1993, p. 1-5.

PÃO de queijo. O sabor mineiro que na versão indústria conquistou o consumidor.
Food Ingredientes, São Paulo, n.12, 2001, p.36-40.

REGINATO, V. KURTS, D. MARCON, M. J. XAVIER, J. M. SCUSSEL, V. M. AMANTE, E. R. Modificação do processo de produção do polvilho azedo visando o aumento na concentração de ácidos orgânicos na água residuária. In: International Workshop advances in cleaner production. São Paulo, 2009.

REGINATO, K.; MARCON, D.; XAVIER, M.J.; SCUSSEL, J.M.; AMANTE, V.M.; VILPOUX,O. Produção brasileira de polvilho azedo. Dissertação (Mestrado em Ciência dos Alimentos) - Universidade Estadual Paulista - UNESP - Botucatu, n.47, 1997, p.1-2.

TELES, F.F.F. Considerações sobre a análise do ácido cianídrico em mandioca e seus produtos manufaturados. In: BANCO DO NORDESTE DO BRASIL. Pesquisas tecnológicas sobre a mandioca, 1972, p. 7-33. 